\title{
Recycling of Liquid waste for effective and satisfactory Pretreatment in Cotton wet Processing
}

\author{
Yenesew Mullu Emrie ${ }^{1}$ and Nalankilli Govindan ${ }^{2 *}$ \\ ${ }^{1}$ Bahir Dar Textile Share Company, Ethiopia \\ ${ }^{2}$ Textile Chemistry Research and Innovation Centre, Bahir Dar University, Ethiopia
}

Submission: January 17, 2019; Published: February 07, 2019

*Corresponding author: Nalankilli Govindan, Textile Chemistry Research and Innovation Centre, Ethiopian Institute of Textile and Fashion Technology, Bahir Dar University, Bahir Dar, Ethiopia

\begin{abstract}
Textile industries are focusing on minimizing their production costs by using sustainable technologies and by inventing new methods. Pretreatment is the heart of textile wet processing. Most of the Textile Companies are using combined pretreatment process with exhaust and semi-continuous method. After the treatment is over, the bath with residual chemicals are drained out into effluent treatment plant. In this study, an attempt has been made to reuse the residual chemicals by replenishing the measured amounts of chemicals again for combined pretreatment process. The concentration of the main chemicals, after pretreatment, before draining was analyzed and quantified. In case of pretreatment process in a Jigger machine, the liquor is drained out after three turns ( 6 ends) with residual chemicals, then the concentrations of $\mathrm{H}_{2} \mathrm{O}_{2}$ and $\mathrm{NaOH}$ was assessed in that. In case of pad-roll bleaching, the fabric roll is rotated in the steaming chamber for twelve hours and washed in a counter current washing machine, then the concentration of chemicals was analyzed after washing is over. Based on the chemical analysis results, by replenishing with measured amounts of chemicals, pretreatment is done in both laboratory scales repeatedly up to four times without changing water and on the bulk production; it has been done by mixing used water and fresh water. The effectiveness of pretreatment was evaluated in terms of absorbency, whiteness, yellowness and the effect in subsequent reactive dyeing and pigment printing in terms of colour strength, colour difference and fastness properties after each pretreatment. It was observed that acceptable results which can fulfill the requirements of the products can be obtained by reusing the pretreatment bath.
\end{abstract}

Keywords: Pretreatment; Reuse; Replenishing; Jigger; Pad-roll

\section{Introduction}

To remove impurities from cotton, a massive amount of water is required in this process per day. It is estimated that on an average, almost 100 liters of water is used to process only $1 \mathrm{~kg}$ of textile goods and thus the water consumption of an average sized textile mill having capacity only 8 tons/day is about 1.6 million liters per day [1]. Among the textile fibers, about $48 \%$ are cotton fibers that we consume as clothing materials all over the globe [2]. All the cotton goods as woven or knit, all goes through the pretreatment process like desizing, scouring, bleaching etc. before dyeing process. These pretreatment processes create huge pretreatment liquor and wash liquor which the industries discharge as textile effluent. All the chemicals used in desizing, scouring and bleaching of cotton fabric do not fully react with it. As a result, pretreatment liquor contains some residual chemicals like caustic soda, peroxide and other auxiliary chemicals $[3,4]$.

The conventional three step pre-treatment process for cotton fabric consists of desizing, scouring and bleaching. Desizing of a grey fabric removes previously added size or starchy material which can be done by using water (rot steeping), acid, enzyme, oxidation chemicals and alkali. Scouring uses alkali to remove oils, fats and waxes to improve the absorbency whereas bleaching uses oxidizing agents to improve the whiteness of the fabric. In a conventional process, scouring and bleaching is done once which results in underutilization of alkali and hydrogen peroxide. But in most of the companies, all these three processes are combined into one, which is a single stage pretreatment process by using jiggers and pad- roll bleaching machines. In case of Jiggers, all the liquor after six ends chemical rotation are drained out; and in case of pad- roll bleaching, after 6-12 hours of rotation in the reaction chamber, the residual chemicals are washed out in washing machine. Most of the time the textile industry uses combined pretreatment process by pad- roll bleaching machine and jiggers. The main chemicals used are $\mathrm{NaOH}, \mathrm{H}_{2} \mathrm{O}_{2}$, Organic stabilizer, wetting agent and Optical Brightening Agent (OBA). The drained-out liquors and wash water can be replenished by adding measured amounts of chemicals and reused again and again based on the concentration of chemicals required for 
pretreatment process. The textile industry utilizes abundant water in pretreatment, dyeing and finishing processes. There is a need to adopt economical practices for the use of water in textile industries. The quantity of water required for textile processing is large and varies from mill to mill depending on the fabrics produced and processed, the quantity and quality of the fabric, processes carried out and the sources of water. The longer the processing sequences, the higher will be the quantity of water required. Bulk of the water is utilized in washing at the end of each process [5].

Recent experiences with water reuse in the textile industry indicate that recycled water, having impurity levels above historically accepted limits, can be used to produce first-quality goods. The minimum water quality for process reuse, therefore, is defined as the treated wastewater containing the highest level or concentration of impurities that will consistently produce an end-product of first quality [6]. The needs of water recycling \& reuse in wet processing has necessitated an appropriate, cost effective water recycling method for reducing the pollution level and fresh water consumption rate [7]. Conservation of water and chemicals by reusing the same bath for several times in cotton pretreatments as desizing, scouring and bleaching [810], reuse of clarified print washes water in washing blankets and screens of the print machine [11], reuse of alkali containing mercerizing wash liquor for scouring and bleaching [12], reuse of the chemicals used in scouring and bleaching of cotton knit [13], reuse of bleaching bath where this bath was also reused four times [14], same liquor bath used for eight times [15], use of unexhausted alkali and oxidizing agent in the scouring and bleaching wastewater respectively to desize a new grey fabric [16], reuse of bleach liquour for eight times [15], reusing of bleaching liquor for scouring [8], reusing of washing water $[9,17]$, reuse of wash water for desizing, scouring and bleaching [18], reusing of washing liquor for desizing [19] are some of studies carried out with considerable success in industrial practice.

The present work is to find the possibilities of reusing the textile pretreatment liquor or wash liquor in disizing, scouring and bleaching of cotton fabric. It is an appropriate, cost effective recycling method for reduction in chemical consumption, fresh water and the pollution level. The pretreatment liquor or wash liquor from single bath was collected periodically and analyzed for presence of useful chemicals and their strength. Then, they will be used for the purpose of combined desizing, scouring and bleaching by replenishing with required quantity of necessary chemicals. Combined pretreated and subsequently dyed fabric samples were assessed for the performances and compared against the samples prepared by conventional method. The focus of this project is on recycling and reusing water and chemicals in the textile pre-treatment process without prior waste water treatment.

\section{Materials and Methods}

\section{Materials}

$100 \%$ cotton fabric (plain-weave, $21 \mathrm{Ne}, 24$ ends per inch, 18 picks per inch, areal density of $147 \mathrm{~g} / \mathrm{m} 2$ ), Jiggers, pad-roll machine, chemicals such as hydrogen per oxide, caustic soda, Organic stabilizer, wetting agent, optical brightening agents, acetic acid, C.I Reactive Blue 19, C.I Pigment Blue 15, sequestering agent, iodine solution, phenolphthalein indicator, Sulphuric acid, hydrochloric acid, common salt, soda ash, potassium per manganate, binder, thickener, emulsifier were used for the study.

\section{Methods}

\section{Method -1}

1) Collecting the drain out pretreatment bath from jiggers after three turns (6 ends).

2) Analyzing chemicals concentration of hydrogen per oxide $\left(\mathrm{H}_{2} \mathrm{O}_{2}\right)$ and caustic soda $(\mathrm{NaOH})$ by titration method.

3) Replenishing the drain bath by adding measured amounts of $\mathrm{H}_{2} \mathrm{O}_{2}$, caustic soda, Organic stabilizer and wetting agent based on the titration results of caustic soda and $\mathrm{H}_{2} \mathrm{O}_{2}$ concentration.

4) Doing combined pretreatment of cotton fabric with the replenished water.

5) Checking and comparing the treated fabric parameters with the conventional treated fabric.

6) Collecting the drain out bath for the second time and repeating procedure 2,3 and 4 .

7) The above procedure will be repeated up to three or four times depending on the concentration of chemicals in the drained-out bath.

\section{Method - 2}

To avoid and minimize contamination of the fabric due to degraded starch and other impurities in the used liquor, it is thought that better to mix used liquor and fresh water in different proportions. These mixing with fresh water can be used for full bleached fabric rather than the one to be dyed / printed. The following three blends of used and fresh water were used.

1) Mixing $70 \%$ used water and $30 \%$ fresh water

2) Mixing $50 \%$ used water and $50 \%$ fresh water

3) Mixing $30 \%$ used water and $70 \%$ fresh water

The chemical concentrations already analyzed in the above method 1 were used for calculating the requirements in this method. Combined pretreatment is done by different jiggers and pad-roll bleaching machine. The chemical recipes which are used in Jiggers $50 \%$ concentrated $\mathrm{H}_{2} \mathrm{O}_{2}$ - 5 gpl, Flake caustic soda $(\mathrm{NaOH})$ - 4gpl, Organic Stabilizer-1g/l, Wetting agent - 1gpl. 


\section{Current Trends in Fashion Technology \& Textile Engineering}

\section{Evaluation}

The fabric absorbency was assessed by the following three methods such as, water drop test (AATCC/ASTM Test Method TS-0180), wicking height (AATCC Test Method 197) and sinking time test (AATCC Test Method 17-1994) methods. Desizing efficiency was evaluated for the presence of residual starch by Tegewa scale rating test which involves iodine absorption and change of colour from no colour change (no starch present) to pale blue to bluish violet (presence of starch size or a blend of starch and synthetic size) to Brown (presence of modified starch or a blend of starch/PVA size) and scale ranging from 8 (best, no starch) to Pale blue to Bluish violet to 1 (Brown). The whiteness index was evaluated as per CIE standard method. The CIE Whiteness Index value (CIE WI) will be determined for the bleached fabric using AATCC test method using a Colour eye Reflectance spectrophotometer 3100 under illuminants D-65, day light and TL84 at $2^{\circ}$ Observer and Yellowness index as per ASTM method E313.

To understand the effect of the above results on the dyeing behavior, reactive dyeing has been done by using C.I Reactive Blue 19 by dyeing in 1\% (on weight fabric) shade for all treated fabrics. As recommended by the dye supplier, the dyeing was done by exhaust dyeing method at $60 \mathrm{oC}$ for 60 minutes. After dyeing is over, the samples were evaluated for color strength
$(\mathrm{K} / \mathrm{S})$ value, color difference $(\Delta \mathrm{E})$, percent reflectance using Colour eye Reflectance spectrophotometer 3100 and Wash fastness, rubbing fastness, Light fastness by following the standard procedures viz. IS: 764:79 Test Method 3, AATCC Test Method 8, AATCC Test Method 16 - Option 3 respectively.

\section{Results and Discussion}

\section{Chemical analysis}

The residual liquor after 6 ends in Jigger were collected and analyzed for two main chemicals, hydrogen per oxide $\left(\mathrm{H}_{2} \mathrm{O}_{2}\right)$ and caustic soda $(\mathrm{NaOH})$ concentration by titration method. The results are presented in Table 1. As observed from Table 1, out of $5 \mathrm{~g} / \mathrm{l}_{2} \mathrm{O}_{2}$ and $4 \mathrm{~g} / \mathrm{l} \mathrm{NaOH}, 1.58 \mathrm{~g} / \mathrm{l}$ and $1.61 \mathrm{~g} / \mathrm{l}$ respectively are still present unutilized that can reused in a single Jigger treatment. The $\mathrm{pH}$ is in the acceptable range for of oxidative bleaching that is around 11.30. The treatment after replenishing is done based on the analysis results. The first analysis was done with the liquor after the conventional pretreatment is over and second analysis is also done with the liquor after first analysis is over, third and fourth analysis are also done from second and third liquor respectively. Above fourth analysis it was not possible as more than $90 \%$ of the water was consumed in replenishing process from once up to four times. Without replacing water, by adding the above measured chemicals, combined pretreatment is done up to four times in the laboratory scale.

Table 1: $\mathrm{H}_{2} \mathrm{O}_{2}$ and $\mathrm{NaOH}$ analysis results.

\begin{tabular}{|c|c|c|c|c|c|}
\hline Parameters & $1^{\text {st }}$ Analysis & $2^{\text {nd }}$ Analysis & $3^{\text {rd }}$ Analysis & $4^{\text {th }}$ Analysis & Average \\
\hline $\mathrm{pH}$ & 10.2 & 11.6 & 12.05 & 11.3 & 11.29 \\
\hline Amount of $\mathrm{H}_{2} \mathrm{O}_{2}$ in $(\mathrm{g} / \mathrm{l})$ & 1.64 & 1.4 & 1.62 & 1.66 & 1.58 \\
\hline Replenished $\mathrm{H}_{2} \mathrm{O}_{2}$ out of $5 \mathrm{gpl}(\mathrm{g} / \mathrm{l})$ & 3.36 & 3.6 & 3.38 & 3.34 & 3.42 \\
\hline Amount of $\mathrm{NaOH}$ in $(\mathrm{g} / \mathrm{l})$ & 0.8 & 1.48 & 2.04 & 2.12 & 1.61 \\
\hline Replenished $\mathrm{NaOH}$ out of $4 \mathrm{gpl}(\mathrm{g} / \mathrm{l})$ & 3.2 & 2.52 & 1.96 & 1.88 & 2.39 \\
\hline
\end{tabular}

The results from Table 2 show that there is no significant difference between the conventional one and the replenished pretreatment in terms of absorbency which is in the order of acceptable level. The drop test results of all samples are less than five seconds. The sinking time test for the conventional and the average values of the replenished is similar. The Tegawa scale rating results shows 8 for the conventional and 5 to 6 for the replenished, the difference is because of hydrolysed starch in the form of dextrin or glucose present in used liquor that is interfering. However, it was found that the samples prepared with used liquor after replenishing can be used for full bleaching, dyeing and printing purpose.

Table 2: Pretreatment test results.

\begin{tabular}{|c|c|c|c|c|c|c|}
\hline \multirow{2}{*}{ Parameters } & \multirow{2}{*}{ Conventional } & \multicolumn{5}{|c|}{ Replenishment } \\
\hline & & $1^{\text {st }}$ & $2^{\text {nd }}$ & $3^{\text {rd }}$ & $4^{\text {th }}$ & Average \\
\hline Drop test (second) & $<5$ & $<5$ & $<5$ & $<5$ & $<5$ & $<5$ \\
\hline Sinking time test (second) & 6.5 & 6.4 & 6.2 & 7.5 & 6 & 6.5 \\
\hline Wicking height test $(\mathrm{cm})$ & 7.9 & 6.5 & 6.3 & 9.5 & 8 & 7.6 \\
\hline Residual starch (Tegawa rating) & 8 & 5 & 5 & 6 & 6 & 5.5 \\
\hline
\end{tabular}

As shown in Table 3 and Figure1, Figure 2, the conventional and the replenished average values are within the acceptable range for the degree of whiteness. In day light as illuminant, the whiteness index was 141.89 and 137.25 for conventional and replenished respectively. The yellowness index value is negative which shows that the whiteness index is higher and as whiteness index increases yellowness index decreases. The differences of yellowness index between conventional and replenished average graphs of two samples are almost over lapped, which means, the difference is insignificant. 


\section{Current Trends in Fashion Technology \& Textile Engineering}

Table 3: Whiteness and Yellowness index.

\begin{tabular}{|c|c|c|c|c|c|c|c|}
\hline \multirow{2}{*}{ Samples } & \multirow{2}{*}{ Illuminant } & \multirow{2}{*}{ Conventional } & \multicolumn{5}{|c|}{ Replenishment } \\
\hline & & & $1^{\text {st }}$ & $2^{\text {nd }}$ & $3^{\text {rd }}$ & $4^{\text {th }}$ & Average \\
\hline \multirow{3}{*}{$\begin{array}{l}\text { Whiteness } \\
\text { index }\end{array}$} & D65 & 140.09 & 129.19 & 136.34 & 143.91 & 133.16 & 135.65 \\
\hline & TL84 & 136.3 & 126.65 & 132.76 & 140.16 & 129.48 & 132.26 \\
\hline & Daylight & 141.89 & 130.38 & 138.12 & 145.67 & 134.85 & 137.25 \\
\hline \multirow{3}{*}{$\begin{array}{l}\text { Yellowness } \\
\text { index }\end{array}$} & D65 & -26.45 & -25.29 & -26.15 & -29.37 & -25.2 & -26.5 \\
\hline & TL84 & -33.55 & -32.82 & -33.55 & -37.52 & -31.96 & -33.96 \\
\hline & Daylight & -26.66 & -25.22 & -26.35 & -29.52 & -25.37 & -26.62 \\
\hline
\end{tabular}

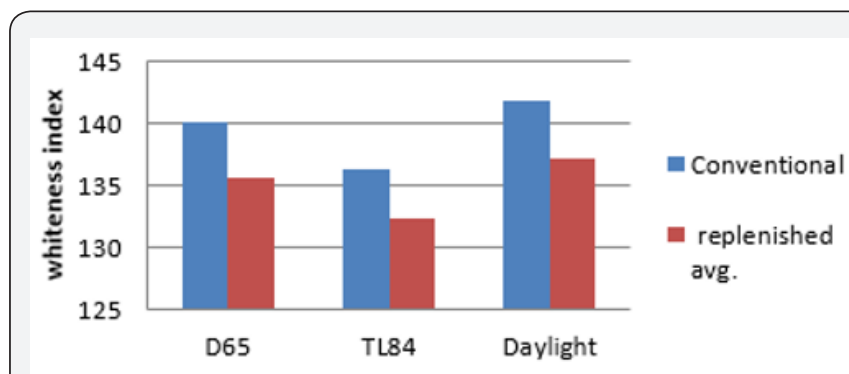

Figure 1: Whiteness index of Conventional \& Replenished pretreated fabrics.

\section{Dyeing performance}

The dyeing performance of treated samples is evaluated with similar shade and dyestuff. Dyeing have also been done all the above pretreated fabrics by using, C.I Reactive Blue19 of $1 \%$ owf. The dyed samples are tested for $\mathrm{K} / \mathrm{S}$ value (color strength), \% Reflectance and Color difference values with $2^{\circ}$ observer and under D65, TL84 and daylight light source by using spectrophotometer at $620 \mathrm{~nm}$ wave length $\left(\lambda_{\max }\right)$. From the results presented in Table 4 and in Figure 3, it is clear that

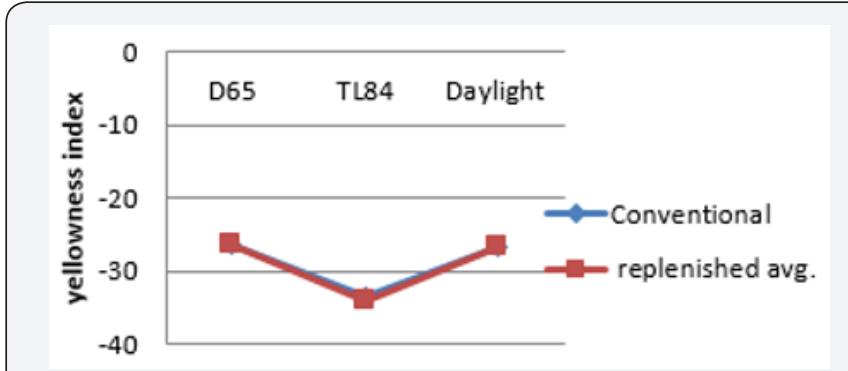

Figure 2: Yellowness index of Conventional \& Replenished pretreated fabrics.

pretreatment with replenished liquor gives little lesser colour strength. The conventional showed a \% Reflectance of $10.78 \%$ and replenished average was $11.41 \%$, due to the fact that, as the $\mathrm{K} / \mathrm{S}$ value increases percent reflectance decreases. The Colour strength was 3.69 for the conventional and ranging from 3.30 to 3.61 with average of 3.44 for the replenished pretreated \& dyed. Color difference between conventional and replenished pretreated was 1.61 to 2.32 with average of 1.7 to 1.9 under all light sources which is quite significant.

Table 4: K/S value, \% Reflectance and Color difference of the dyed samples.

\begin{tabular}{|c|c|c|c|c|c|c|c|}
\hline \multirow{2}{*}{ Samples/ Factors } & \multirow{2}{*}{ Illuminant } & \multicolumn{6}{|c|}{ Replenishment } \\
\hline & & Conventional & $1^{\text {st }}$ & $2^{\text {nd }}$ & $3^{\text {rd }}$ & $4^{\text {th }}$ & Average \\
\hline $\mathrm{K} / \mathrm{S}$ value & \multirow{2}{*}{ D65 } & 3.69 & 3.43 & 3.3 & 3.43 & 3.61 & 3.44 \\
\hline \% Reflectance & & 10.78 & 11.44 & 11.78 & 11.43 & 10.97 & 11.41 \\
\hline \multirow{3}{*}{ Color Difference } & D65 & \multirow{3}{*}{ Reference } & 1.82 & 2.31 & 2.05 & 1.63 & 1.95 \\
\hline & TL84 & & 1.61 & 2.02 & 1.81 & 1.48 & 1.73 \\
\hline & Daylight & & 1.88 & 2.32 & 2.06 & 1.65 & 1.98 \\
\hline
\end{tabular}

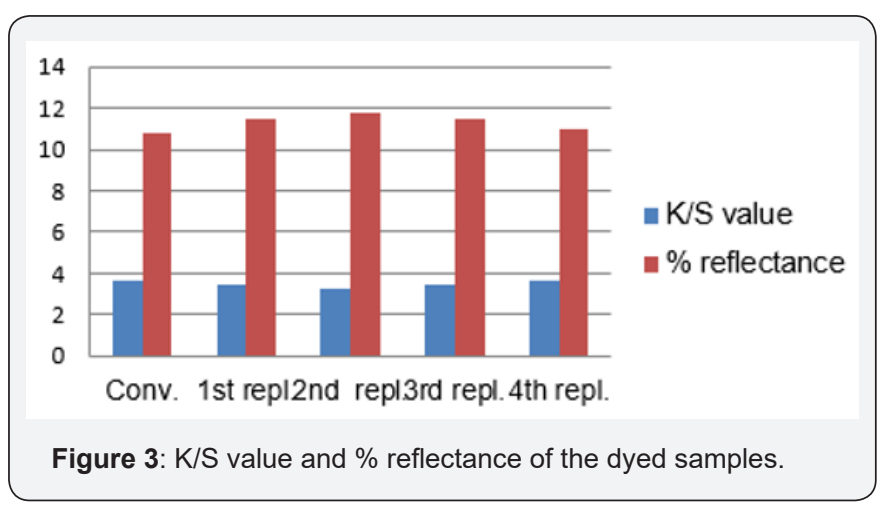

The fastness properties of both the conventional and replenished pretreated \& dyed samples have good results as it is shown by the grey scale readings in Table 5 . The washing fastness results of both staining and fading rating was in the range of 4-5 and 4-5 dry \& 4 wet rubbing values for both conventional and replenished average.

The laboratory results are not reproducible in bulk stage in general. The main reasons are:

a. Material to liquor ratio (MLR) difference between laboratory tests and bulk. 1:20 was used in laboratory, but at the bulk in jiggers it was about 1:5. 


\section{Current Trends in Fashion Technology \& Textile Engineering}

Table 5: Fastness of Dyed Fabrics.

\begin{tabular}{|c|c|c|c|c|c|}
\hline \multirow{2}{*}{ Parameters } & \multirow{2}{*}{ Conventional } & \multicolumn{4}{|c|}{ Replenishment } \\
\cline { 3 - 6 } & & $\mathbf{1}^{\text {st }}$ & $\mathbf{2}^{\text {nd }}$ & $3^{\text {rd }}$ & $\mathbf{4}^{\text {th }}$ \\
\hline Washing fastness & $4 / 4.5$ & $4 / 4.5$ & $4 / 4.5$ & $4 / 4.5$ & $4 / 4.5$ \\
\hline Dry rubbing fastness & $4-5$ & $4-5$ & $4-5$ & $4-5$ & $4-5$ \\
\hline Wet rubbing fastness & 4 & 4 & 4 & 4 & 4 \\
\hline
\end{tabular}

b. Temperature and time have also an effect in reproducibility of bulk production.

c. For ready- for- dyeing fabric, there must be a separate desizing process before scouring, but in some factories desizing is not done. The above all results may be reproduced if a soft flow machine.

\section{Bulk Results}

Keeping the laboratory results in mind and considering contamination of water because of decomposed starch present in liquor, the following experiments have been done on the mass production machines by using small jiggers. The drained- out liquor was used for pretreatment again in Jigger that had a capacity of 300 liters of solution and can load 135kg of fabric.

The collected liquor had $1.6 \mathrm{~g} / \mathrm{l}$ of $\mathrm{H}_{2} \mathrm{O}_{2}$ out of $5 \mathrm{~g} / \mathrm{l}$ and $1.4 \mathrm{~g} / \mathrm{l}$ of $\mathrm{NaOH}$ out of $4 \mathrm{~g} / \mathrm{l}$. The remaining amounts of chemicals and other auxiliary chemicals were added to make up the conventional recipe before using again jigger. Then, as shown in the Table 6, the pretreatment was carried out and the performance was assessed and compared with conventional. The chemical amounts in Table 6 are based on the standard recipe, $\mathrm{H}_{2} \mathrm{O}_{2}-5 \mathrm{~g} / \mathrm{l}, \mathrm{NaOH}-4 \mathrm{~g} / \mathrm{l}$, Organic stabilizer- $20 \%$ of $\mathrm{H}_{2} \mathrm{O}_{2}$, wetting agent- $1 \mathrm{~g} / \mathrm{l}$ and OBA $-0.6 \mathrm{~g} / \mathrm{l}$.

Table 6: Replenished amounts of chemicals in the Bulk trial.

\begin{tabular}{|c|c|c|c|c|c|}
\hline Chemicals & Conventional & $\mathbf{1 0 0 \%}$ used liquor & $\mathbf{7 0 \%}$ used + 30\% fresh & $\mathbf{5 0 \%}$ used + 50\% fresh & $\mathbf{3 0 \%}$ used + 70\% fresh \\
\hline $\mathrm{H}_{2} \mathrm{O}_{2}(\mathrm{~g})$ & 1500 & 1020 & 1165 & 1260 & 1355 \\
\hline $\mathrm{NaOH}(\mathrm{g})$ & 1200 & 780 & 905 & 990 & 1075 \\
\hline Organic Stabilizer $(\mathrm{g})$ & 300 & 205 & 230 & 250 & 270 \\
\hline Wetting agent $(\mathrm{g})$ & 300 & 300 & 300 & 300 & 300 \\
\hline OBA (g) & 180 & 180 & 180 & 180 & 180 \\
\hline
\end{tabular}

With these, after doing pretreatment on jigger, whiteness and yellowness index are checked and compared with the conventional with same chemical recipes. In addition to this, on the treated fabrics, pigment printing has been done with C.I Pigment Blue 15 and the performance was assessed in terms of fastness, color strength, color difference and percent reflectance. The whiteness and yellowness index values of the bulk samples are summarized in Table 7 and in Figure 4. It is clear that the whiteness index is decreasing, and yellowness index is increasing from the conventional to fourth replenished pretreated. The reason for this is the decomposed starches in the used liquor are reacting with per oxide and interfering in the overall process. Even though, it was a decreased result, the variation is not too much and it can be used for printing, grounding and off-white fabric. To make more white fabric per oxide amount must be increased to compensate the reaction. C.I Pigment Blue 15 printed samples K/S value (color strength); \% reflectance and Color difference values were tested at $600 \mathrm{~nm}$ wavelength $\left(\lambda_{\max }\right)$ Table 8.

Table 7: Whiteness and Yellowness index value of the bulk trial.

\begin{tabular}{|c|c|c|c|c|c|c|c|}
\hline $\begin{array}{c}\text { Samples/ } \\
\text { Factors }\end{array}$ & Illuminant & Conventional & $\begin{array}{c}70 \% \text { fresh \& } \\
30 \% \text { used }\end{array}$ & $\begin{array}{c}50 \% \text { fresh \& } \\
\mathbf{5 0 \%} \text { used }\end{array}$ & $\begin{array}{c}30 \% \text { fresh } \& \\
70 \% \text { used }\end{array}$ & $100 \%$ used & Average \\
\hline \multirow{3}{*}{$\begin{array}{l}\text { Whiteness } \\
\text { index }\end{array}$} & D65 & 101.26 & 88.64 & 86.74 & 82.62 & 65.15 & 80.79 \\
\hline & Daylight & 102.62 & 89.8 & 87.83 & 83.74 & 65.67 & 81.76 \\
\hline & $S$ & 99.13 & 87.5 & 85.86 & 81.76 & 65.85 & 80.24 \\
\hline \multirow{3}{*}{$\begin{array}{l}\text { Yellowness } \\
\text { index }\end{array}$} & D65 & -9.41 & -4.63 & -3.44 & -2.88 & 4.22 & -1.68 \\
\hline & Daylight & -9.71 & -4.94 & -3.74 & -3.22 & 3.96 & -1.99 \\
\hline & TL84 & -9.9 & -4.83 & -3.56 & -2.97 & 4.56 & -1.7 \\
\hline
\end{tabular}




\section{Current Trends in Fashion Technology \& Textile Engineering}

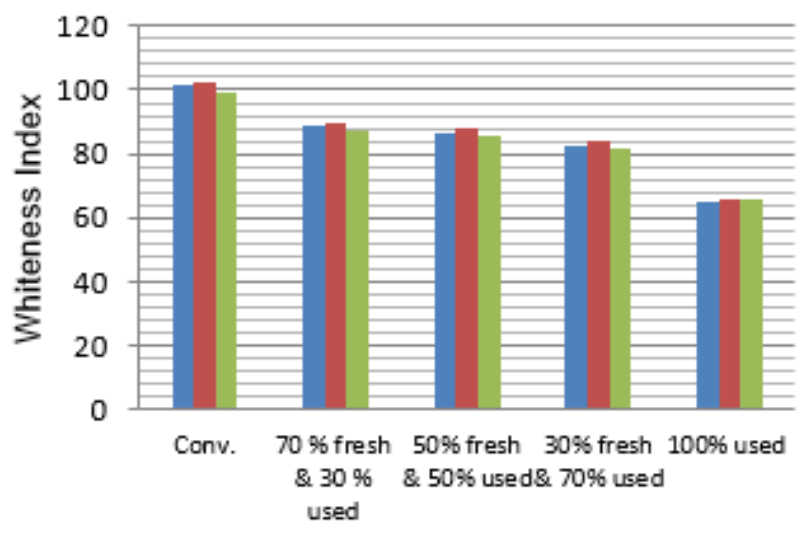

D65

naylight

u Scandesnt

Figure 4: Whiteness index from bulk trial.

Table 8: K/S value, \% Reflectance and Color difference of the printed samples.

\begin{tabular}{|c|c|c|c|c|c|c|c|}
\hline \multirow{2}{*}{ Samples } & \multirow{2}{*}{ Illuminant } & \multirow{2}{*}{ Conventional } & \multicolumn{5}{|c|}{ Replenishment } \\
\hline & & & 1st & 2nd & 3rd & 4th & Average \\
\hline $\mathrm{K} / \mathrm{S}$ value & D65 & 4.81 & 4.57 & 4.57 & 4.7 & 4.52 & 4.59 \\
\hline$\%$ Reflectance & & 8.67 & 9.05 & 9.05 & 8.84 & 9.13 & 9.02 \\
\hline \multirow{3}{*}{$\begin{array}{c}\text { Color } \\
\text { Difference }\end{array}$} & D65 & \multirow{3}{*}{ Reference } & 0.77 & 1.01 & 1.29 & 1.62 & 1.17 \\
\hline & Daylight & & 0.78 & 1.00 & 1.33 & 1.54 & 1.16 \\
\hline & TL84 & & 0.8 & 1.06 & 1.28 & 1.65 & 1.20 \\
\hline
\end{tabular}

The K/S values of the printed samples showed very minor variation between conventional and replenished pretreated. It is 4.80 for the reference and 4.59 for the replenished (average). The reflectance values showed a little increase, but the difference is less than 1 Table 9. The color difference was around 1.1 under

Table 9: Pigment printing parameter test results of the bulk product. three light sources. The fastness properties of the printed samples are within acceptable range based on gray scale value. Both staining and fading of washing fastness it 4; dry rubbing and wet rubbing staining values have 4 and 3 respectively Figure 5 .

\begin{tabular}{|c|c|c|c|c|c|}
\hline Fastness/Parameters & Conventional & $\mathbf{1 0 0 \%}$ used & $\mathbf{5 0 \%}$ used $\mathbf{5 0} \mathbf{5}$ fresh & $\mathbf{7 0 \%}$ used \& 30\% fresh & $\mathbf{3 0 \%}$ used \& $\mathbf{7 0} \%$ fresh \\
\hline Washing fastness* & $4 / 4.5$ & $4 / 4.5$ & $4 / 4.5$ & $4 / 4.5$ & $4 / 4.5$ \\
\hline Dry rubbing fastness* & 4 & 4 & 4 & 4 & 4 \\
\hline Wet rubbing fastness* & 3 & 3 & 3 & 3 & 3 \\
\hline
\end{tabular}

*Both Change in colour and staining on white

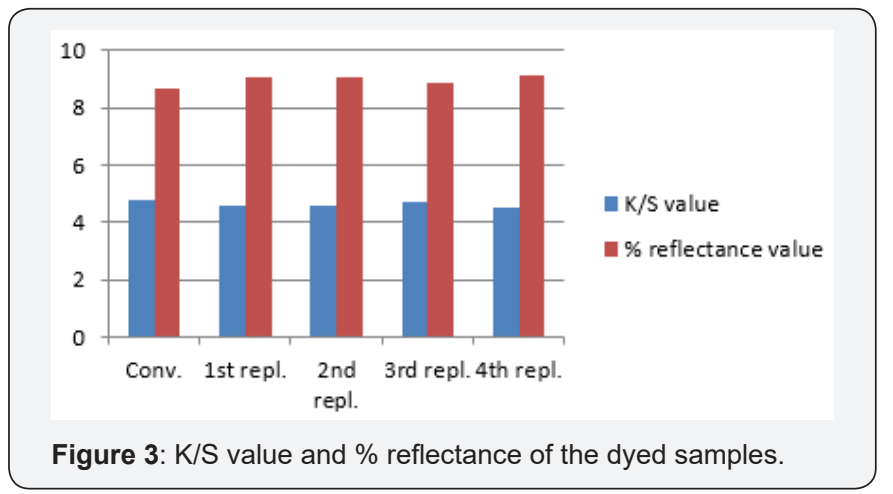

\section{Conclusion}

Based on the results, it can be concluded that pretreatment liquor and wash liquor can be reused in the pretreatment process of cotton instead of fresh water. The pretreatment liquor and wash liquor can safely be reused after replenishing with measured amounts of $\mathrm{H}_{2} \mathrm{O}_{2}, \mathrm{NaOH}$ and other auxiliary chemicals based on the analysis results for the scouring-bleaching purpose of next batch with satisfactory bleaching, printing and dyeing performance. As a result, the reuse of pretreatment liquor ensures saving of a lot of chemicals consumption, water consumption as well as reduce waste water discharge and effluent load and the reuse of wash liquor ensures the reduced consumption of huge amount of fresh water.

\section{Acknowledgements}

The authors would like thank Bahir Dar Textile Share Company and Ethiopian Institute of Textile and Fashion Technology for providing the facilities to carry out this research. 


\section{Current Trends in Fashion Technology \& Textile Engineering}

\section{Conflict of Interest}

Authors declare no conflict of interest.

\section{References}

1. Allègre C (2006) Treatment and reuse of reactive dyeing effluents. Journal of Membrane Science 269(1-2): 15-34.

2. Broadbent AD (2001) Basic Principle of Textile Coloration. Society of Dyers and Colourists, UK.

3. Choudhari, Edward Menezes, Mrinal (2011) Pre-treatment of Textiles Prior to Dyeing. Textile Technology. Peter Hauser, IntechOpen: 221261

4. Sonaje NP, Chougule MB (2013) Comparison Of Whiteness Index Of Cotton Fabric Bleached With Recycled Wastewater. International Journal of Innovative Research in Science, Engineering and Technology 2(8): 3946-3951.

5. Chougule NP, Sonaje MB (2015) An experimental study on water reuse in textile pretreatments especially in scouring and bleaching. International Journal of Advanced Research 4(7): 701-711.

6. Lanza, kerry M (2007) An Alternative for Textile Wastewater, Water and Process Technologies. General Electric Company. r125 EN Aug-07.

7. Abu Shaid, Showkat Osman Md, Abdul Hannan Md, Rahman Bhuiyan (2013) Direct Reusing of Textile Wastewater in Scouring-Bleaching of Cotton goods devoid of any Treament, International Journal of Engineering Research and Development 5(8): 45-54.

8. Chougule NP, Sonaje MB (2014) Experimental studies on Municipal Wastewater Recycling and Water Conservation in Cotton Textile Wet Processing, International Journal of Current Engineering and Technology 4(3): 1862-1869.

9. Shaikh, Muhammad Ayaz (2009) Water conservation in textile industry, Pakistan Textile Journal 58(11): 48-51.
10. Raleigh (1972) Water pollution reduction through recovery of Desizing Wastes. Environmental Protection Agency Office of Research and Monitoring, National service centre for Environmenal Publications, USA.

11. Chavan SV, Shindale RP (2016) Replenishment of Pretreatment Bath- A Measure for Minimizing Effluent Load. Journal of Polymer and Textile Engineering 3(5): 15-25.

12. Sujata Saxena, Raja ASM, Arputharaj A (2017) Challenges in Sustainable Wet Processing of Textiles. Textile Science and Clothing Technology: 43-79.

13. Abdul Hannan Md, Rakibul Hasan Chowdhury (2016) Scope of reusing pretreatment exhaust liquor and pretreatment wash liquor in new pretreatment process, Bangladesh Textile Today 9(7): 30-34.

14. Rachana S, Harane, Ravindra V, Adivarekar (2013) Simple Approach For Cost Effective Reuse Of Water In Pretreatements Of Cotton. International Journal of ChemTech Research 5(2): 671-675.

15. Sonaje, Nitin P (2015) An experimental study on water reuse in textile pretreatments especially in scouring and bleaching. International Journal of Advanced Research 3(3): 707-711.

16. Rachana Harane, Ravindra Adivarekar (2017) A frugal way of reusing wastewater in textile pre-treatment process. Journal of Water Process Engineering 16(2): 163-169.

17. Balachandran S, Rudramoorthy R (2008) Efficient Water Utilisation in Textile Wet Processing, Institution of Engineers(I) Journal-TX 89(3): 24-30.

18. Brita K (2010) Water Conservation in Textile Industry, yarns and fibers. Pakistan Textile Journal 59(7): 86-94.

19. Smith B (1986) Identification and reduction of pollution sources in textile wet processing. Health and Natural Resources, North Carolina Board of Science and Technology, Office of Waste Reduction, USA.

\section{Your next submission with Juniper Publishers} will reach you the below assets

- Quality Editorial service

- Swift Peer Review

- Reprints availability

- E-prints Service

- Manuscript Podcast for convenient understanding

- Global attainment for your research

- Manuscript accessibility in different formats

( Pdf, E-pub, Full Text, Audio)

- Unceasing customer service

Track the below URL for one-step submission https://juniperpublishers.com/online-submission.php 